\title{
Significance of decision-making for LCA methodology
}

\author{
Anne-Marie Tillman* \\ Environmental Systems Analysis, Chalmers University of Technology, S-412 96 Göteborg, \\ Sweden \\ Accepted 2 August 1999
}

\begin{abstract}
Decision-making is central to life cycle assessment (LCA), both in the sense that LCA may be used as decision support and in the sense that different methodological choices in LCA are relevant to different applications. This latter issue is pursued in this paper: i.e., how the decision-making context, and thus goal definition, may be used to guide methodological choices in LCA. A distinction is made between a retrospective or accounting perspective and a prospective perspective, where the consequences of alternative actions are investigated. This has significant implications for LCA guidelines, including the standard on LCA compiled by the International Standardization Organization (ISO). (C) 2000 Elsevier Science Inc. All rights reserved.
\end{abstract}

Keywords: Life Cycle Assessment; Decision-making; LCA methodology; LCA applications

\section{Introduction}

Life cycle assessment (LCA) is a systems analysis method, as indicated by the occurrence of multidisciplinarity, teleological features, the presence of large (complex) systems and handling of a systems model, and the existence of case studies and their iterative nature [1]. There are numerous purposes of LCA. The ISO 14040 standard [2] lists the following applications: identification of improvement possibilities, decision-making, choice of environmental performance indicators, and market claims. Another important application of LCA is that of learning-e.g., learning about environmental issues both in general and as associated with the product system studied and learning about the relationships of the production system stud-

\footnotetext{
* Corresponding author.
} 
ied, even beyond the boundaries of the entity performing the LCA [3]. All these applications aim at change, or improvement: some in more direct ways (decision-making), some in more indirect ways, such as influencing market behavior or identifying improvement possibilities.

Thus, LCA has implications for decision-making. However, decisionmaking has implications for LCA as well; i.e., how systems are modeled in LCA depends on the purpose of the study. This paper will pursue the latter subject: i.e., which methodological choices in LCA are relevant to which applications? The paper is limited to inventory methodology, although similar reasoning may be applied to impact assessment.

\section{Main categories of LCAs and their characteristics}

There are two main categories of LCA. These may be called retrospective and prospective, or LCA with an accounting perspective and LCA modeling the effects of changes. The categories may be broken down further, as in the LCANET report [4].

It is my impression that many of the controversies in the debate on LCA methodology have stemmed from the failure to recognize the distinction between these two perspectives, or even the failure to recognize the occurrence of a different type of LCA than the one being advocated. The confusion of the two perspectives is also evident in many sets of LCA guidelines, including the ISO standards. For instance, the ISO 14041 standard on goal and scope definition and inventory analysis states that "The choice of elements of the physical system to be modelled is dependent on the definition of the goal and scope of the study" [5]. On the other hand, the standard states that ideally all flows should be followed until they are elementaryi.e., to the boundary between the technical system and the natural system. Reasons for not complying with this recommendation may be lack of time, data, or resources, or if including unit processes does not significantly change the overall conclusions of the study [5]. Nothing, however, is said about relevance in relation to goal definition. The recommendation to trace all flows to the "cradle" or the "grave" implies an accounting perspective, that everything should be included and accounted for, whether relevant or not. The criteria as to whether a unit process may be omitted are based on whether its flows are negligible (or not); i.e., they are not based on its relevance to a potential change in the system being modeled.

The main features of life cycle inventory (LCI) models according to the two types are shown in Table 1.

Table 1 is explained and discussed in the following case study on waste water treatment [6]. The main question in the LCA study was: What are the environmental consequences of changing the treatment of waste water from households in a well defined area? The change would be to send the water currently sent to an existing, centralized waste water treatment plant 
Table 1

Characteristics of retrospective and prospective LCI models, respectively

\begin{tabular}{lll}
\hline \multirow{2}{*}{ Characteristic } & Type of LCA & \\
\cline { 2 - 3 } System boundaries & Retrospective & Prospective \\
\hline Allocation procedure & Additivity & Parts of system affected \\
& Completeness & \\
Reflecting causes of system & Reflecting effects of change \\
System subdivision & Partitioning & System enlargement \\
\hline
\end{tabular}

instead to a more local system and to increase recycling of plant nutrients. Three alternative scenarios were compared: (1) the existing system with centralized sewage treatment, including heat recovery to a district heating system; (2) a system of local treatment, with increased recycling of plant nutrients but with less heat recovery; and (3) a system with urine separation, allowing for even higher degrees of plant nutrient recycling. The waste water system was modeled as in Fig. 1.

\subsection{System boundaries and allocation}

In LCAs aimed at modeling effects of a change, relevance to the change at hand is the guiding principle as to inclusion. Any part of a system not affected by the change at hand may be left out of the study. In our example, this applies to the source of the waste water: i.e., the households and some of its inflows (food, detergents, heat, etc.) that would be the same regardless of how the waste water is treated. Drinking water consumption, on the other hand, would be affected, in that different toilets modeled in the different scenarios used different amounts of clean water. The mode of collection and transportation (by truck or by sewer) of the waste water differed between alternatives and thus was included. Had the waste water been collected and transported in the same way in each alternative, this part of the cycle could have been excluded.

The system as described in Fig. 1 has several functions. It treats the sewage, but it also delivers heat and plant nutrients. Recycling of plant nutrients reduces the need for other types of fertilizers, if agricultural production is assumed to be constant. Production of heat energy and biogas reduces the need for other energy sources, provided demand for heat does not change. This was modeled through system enlargement; i.e., the model was expanded to include all activities that would be affected by a change in the sewage system, as described in Fig. 2. Useful flows leaving the waste water system were followed to the point where they can be used. The system was then compensated with alternative production of energy and fertilizer.

Had the study been about describing the environmental performance of a waste water system, with no changes in mind, a retrospective accounting 


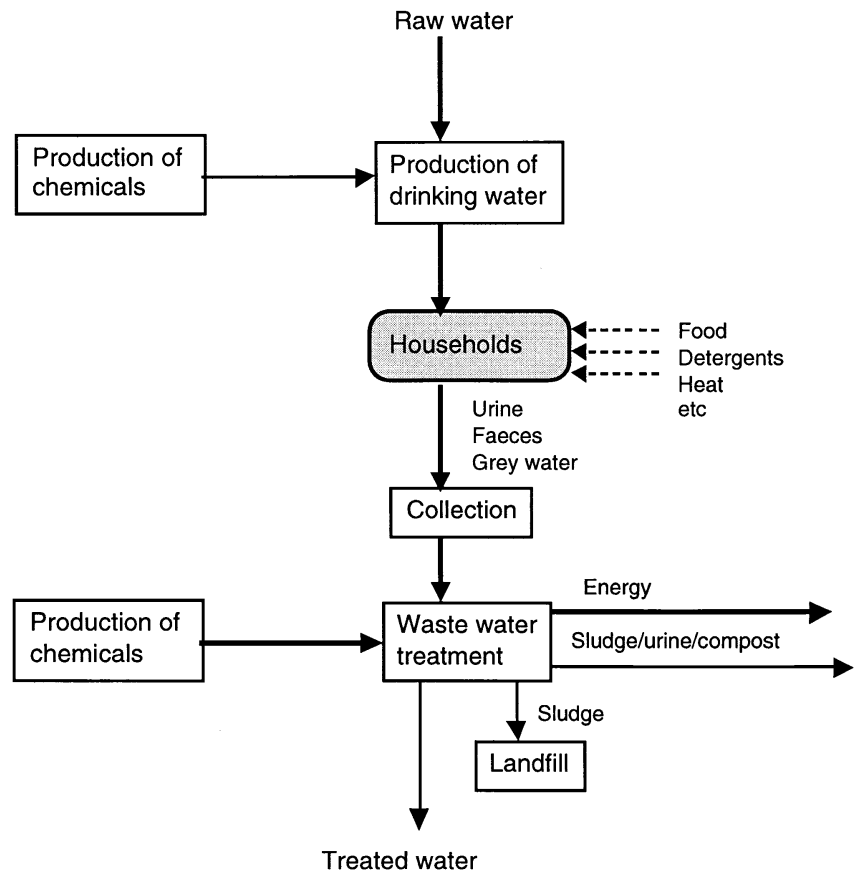

Fig. 1. Flowchart for treatment of waste water from households. Square boxes represent activities included in the model; shaded boxes with rounded corners represent excluded activities.

perspective could have been applied. What then would characterize such a study in terms of system boundaries and allocation? Activities in the middle of the system, such as collection and transportation of the waste water to the treatment facility, could under no circumstances have been omitted (or no circumstances other than insignificance). Interactions with fertilizer production and energy production are of less interest for the waste water system as such. Thus, the system's environmental burdens could have been allocated (i.e., partitioned) among its different functions. Another option would have been just to report a flow budget over the unallocated, multifunctional system.

An important characteristic of an accounting LCA is that of additivity, so that, for example, a LCA of a waste water system can easily be added to one for, say, a detergent. Completeness, or at least a convention about what is included in the system, is a prerequisite for additivity. Issues debated in the LCA community, such as what activities may be insignificant (i.e., cut-off rules) and whether production of capital goods should be included in the system, relate to the idea of LCA as an accounting method. The guiding idea may be expressed as "LCA results of all the products in the 


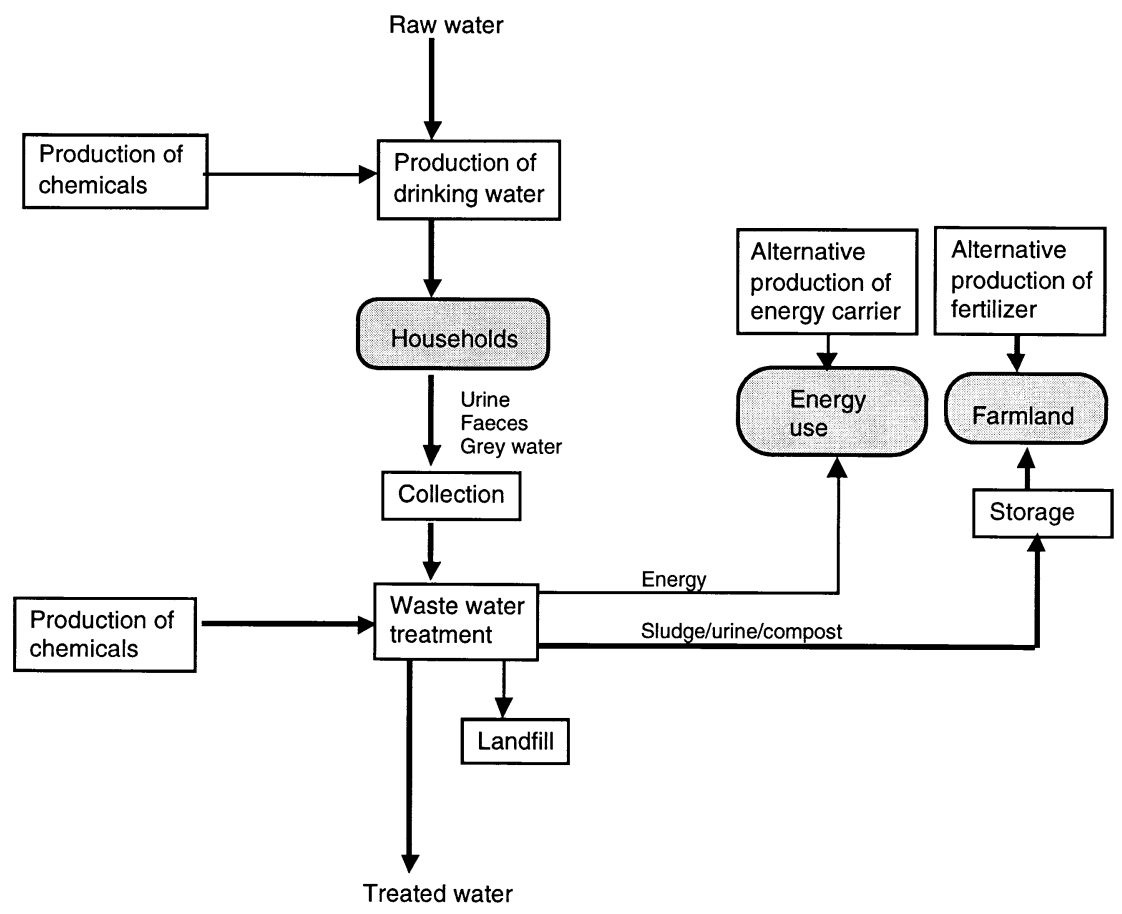

Fig. 2. System enlargement as applied to the multiple functions of a waste water system. Square boxes represent activities included in the model; shaded boxes with rounded corners represent excluded activities.

world should add up to the total environmental impact in the world." Expressions such as $100 \%$ rule grow out of this principle.

Allocation procedures have been among the most heavily debated issues of life cycle inventory (LCI) methodology. The ISO standard on inventory methodology [5], which may be seen as the consensual outcome of the debate, does not recognize the difference between the two perspectives and recommends an order of preference for allocation procedures. It gives precedence to the prospective perspective, because system enlargement is preferred over partitioning of environmental burdens. System enlargement was applied in the waste water case study, because the study was designed to reflect the consequences of a change that would have affected the surrounding technical system.

It has often been stated that allocation procedures should reflect causalities. Closer inspection reveals that there are at least two categories of causal relationships on which allocation can be based (see Fig. 3) [7]. Causeoriented causalities describe the relationships between the investigated system and its causes; effect-oriented causalities are the relationships between the investigated system and its effects. Economic profit from a system 


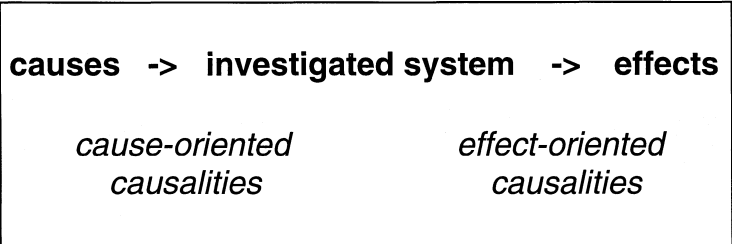

Fig. 3. Two different types of causal relationships that can be used as a basis for allocation.

is one of the reasons a system exists, and it has been proposed that gross sales value be used as a basis for allocation [8]. This reflects an accounting, or retrospective, perspective. System enlargement is done to describe the full effects of a change, and is thus an example of an allocation procedure based on effect-oriented causality.

\subsection{System subdivision}

To guide the analyst in the choice of the type of data to use in the model, I have found the subdivision of the system into a foreground and a background system useful for change-oriented LCAs. The concepts have no relevance for accounting LCAs, because in this type of LCA all parts of the system are equally focused. The concepts were developed in the SETAC working group on enhancement of inventory methodology [9]. The foreground system is the collection of processes on which measures may be taken concerning their selection or mode of operation as a result of decisions based on the study. The background system consists of all other modeled processes influenced by measures taken in the foreground system. A sufficient (but not necessary) condition for a process or group of processes to be in the background is that the exchange with the foreground takes place through a homogeneous market.

Both foreground and background are affected by changes following decisions on the system analyzed. Effects in the foreground system result directly from those decisions. Effects in the background system are caused indirectly by effects in the foreground system-associated, for example, with changes in supply or demand of goods and services. The distinction between foreground and background systems has nothing to do with the environmental importance of those effects. Effects on environmental loads may be largest in either the foreground or the background.

In the waste water case study, concepts very similar to foreground and background systems (i.e., core system and enlarged system) were arrived at, not so much through theoretical reflection as through a practical means of making consistent methodological choices and of presenting the results in a meaningful way [6] (see Fig. 4). The system boundaries between foreground and background have in this example been slightly redrawn, as compared with the original case study, to fit in with the more theoretically reflected concepts of foreground and background. 


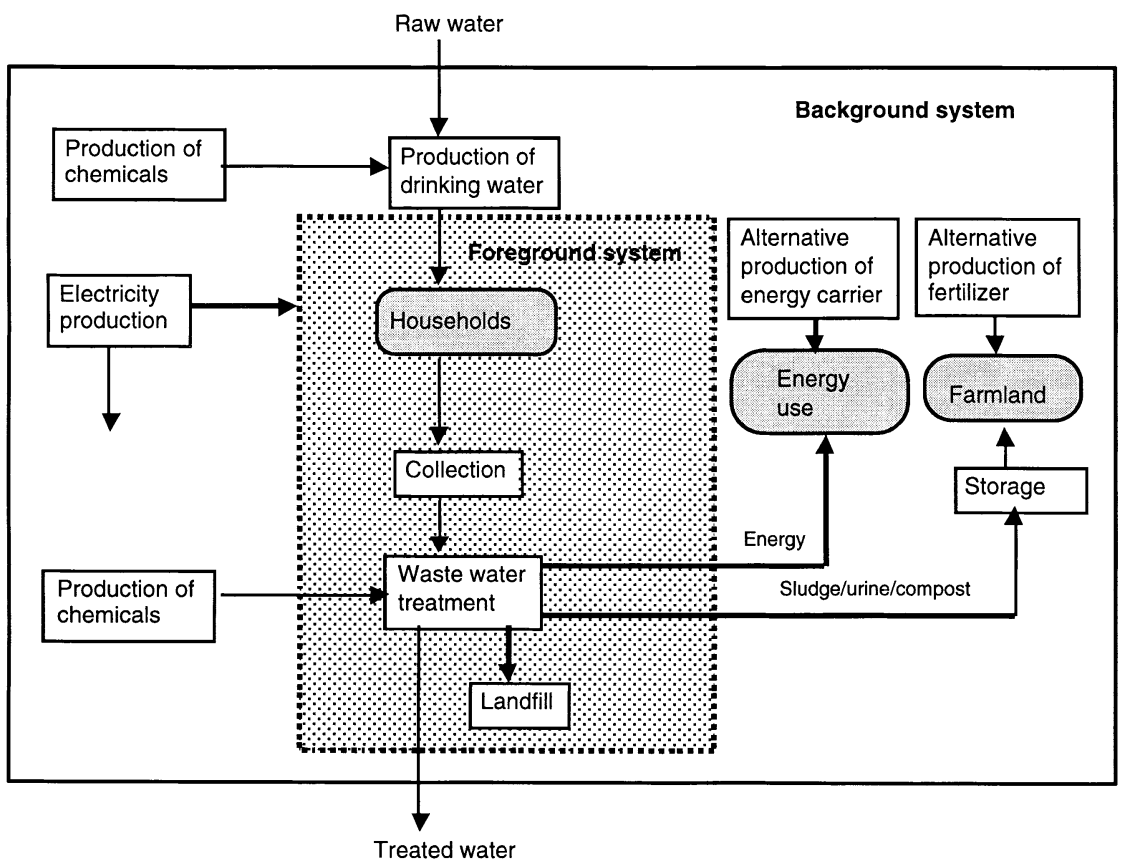

Fig. 4. Flowchart for treatment of waste water from households. The foreground system represents those activities on which measures may be taken as a result of decisions based on the study. The background system represents all other activities affected by a change of waste water treatment system. For simplicity, electricity delivered to other parts of the background system is indicated only generally. Square boxes represent activities included in the model; shaded boxes with rounded corners represent excluded activities.

Although the study was performed as a research activity, it was done as if the intended audience were those responsible for the waste water systems in the studied area. Thus, the waste water system was defined as the foreground system, and all the other technical systems affected by changes in the waste water system were defined as background systems. For the foreground system, data representing annual averages of specific processes were used, whereas the technical systems in the background were assumed to be marginally affected. This goes not only for the parts included through system enlargement (i.e., production of heat and fertilizer) but also for other parts of the background system, such as electricity production.

\subsection{Choice of data}

Which data are most relevant when modeling a system also depends on the purpose of the study. Which types of data do best represent the system? The issues debated include whether to use site-specific data or data representing an average over a population of similar processes and whether to use data representing average behavior of a process (or population of 
Table 2

Relevance of retrospective and prospective perspective to different types of LCA applications

\begin{tabular}{lll}
\hline Type of LCA & Retrospective & Prospective \\
\hline Applications & Learning & Changes in: \\
& Identification of improvement & $\begin{array}{l}\text { product design } \\
\text { process design } \\
\text { possibilities } \\
\text { Market claims }\end{array}$ \\
& $\begin{array}{l}\text { aiming for change } \\
\text { aiming }\end{array}$ \\
\hline
\end{tabular}

processes) or data representing marginal performance. The issue of average versus marginal was discussed in the SETAC working group on enhancement of inventory methodology [9] and again in the LCANET report [4]. The LCANET report recommends data representing average performance for accounting LCAs and data representing different types of marginal performance where effects of changes are modeled (except for long term strategic planning, where expected future averages are recommended).

As for the question of whether to use data representing specific processes or averages over a population of processes, this also must be determined by the goal of the study. For LCIs modeling effects of changes, it must be considered whether the change involves a population of processes, which may be the case when the LCA is meant to support decisions on regulatory measures, or whether the change involves specific processes.

\section{Which type of LCA for which purpose?}

Although it may be argued that all types of LCA are done with the same general purpose (i.e., environmental improvement, which in turn implies change), not all LCAs are made to support decision-making directly, in the sense of choice between formulated alternative actions. Decisionmaking may be described generally as a procedure where (1) a problem is formulated, (2) alternatives are formulated, and (3) a choice is made between alternative solutions to the problem [1].

LCA may assist both in defining the problem and in the assessment of alternatives. In the early phases of a decision-making procedure, the problem is defined and alternative solutions to the problem are generated. The environmental performance of the product's life cycle, and thus its improvement possibilities, are essentially unknown. A description of the present status is then needed, which is supported by an accounting LCA (Table 2). Learning and identification of improvement possibilities, two of the applications in Table 2, thus refer to the early phases of the decisionmaking procedure. Table 2 is not, however, meant to imply that nothing can be learned from change-oriented LCA, or that no improvement possibilities can be identified in such a study.

Often some things are known about a product's life cycle before a formal 
quantitative LCA is made, and some improvement possibilities may have been thought of beforehand. A LCA performed under such conditions is more related to the later phases of the decision-making procedure (assessment and choice between alternatives), and a change-oriented methodology is thus relevant.

Concerning LCAs performed for the purpose of making market claims (e.g., environmental product declarations) [10], in which an LCA-based eco-profile is used in market communication, there are a number of arguments for using an accounting approach [11].

1. Acceptability. For an environmental product declaration system based on LCA to be operative there must be a generally accepted set of rules for how to perform such LCAs. To establish a consensus on (a) an approach allowing for system expansion and use of marginal data and (b) an approach as to which marginals and in which way the system should be expanded will probably be impossible.

2. Additivity and completeness. Additivity is important for an environmental product declaration system, because it should enable each producer to add the environmental impacts of his/her processes the accumulated environmental impacts over the life cycle thus being accounted for. For the same reason, completeness in the sense that no part of the life cycle may be omitted (unless negligible or omitted by convention) is an important feature of this type of LCA.

3. Unknown alternatives. If a LCA for environmental product declaration purposes is to model effects of changes, which changes would be the relevant ones? It is impossible to know which product a purchaser would choose over the one with the environmental product declaration. It is also very difficult to estimate the scale of change possibly caused by the environmental product declaration. The scale, in turn, may be important in determining the marginal capacities.

4. Feasibility. System enlargement implies a larger system and thus more data to collect.

When LCAs are used to support well-defined decisions (i.e., a choice between two or more alternative actions), decision-making is best supported by models accounting for the full effects of the considered actions; i.e., the LCA results should reflect the environmental consequences of the decision. A change-oriented approach is thus relevant for evaluating improvement possibilities.

\section{Implications for LCA guidelines}

In several sets of LCA guidelines, including the ISO standard and the SETAC code of practice [12], there is general recognition that methodological choices should be made in relation to the goal and scope of the study. However, when it comes to details, absolute statements as to which method 
is preferable are made. This applies especially to the allocation procedure in ISO 14041 [5], which (in abbreviated form) states that

1. whenever possible allocation should be avoided by increased level of detail or system expansion;

2. where allocation cannot be avoided, the system's inputs and outputs should be partitioned among its different products or functions in a way that reflects the underlying physical relationships between them; and

3. where physical relationship alone cannot be established or used as a basis for allocation, allocation should reflect other relationships between the products or functions of the system, such as economic value.

This ranking of allocation procedures contradicts more general statements made earlier in the same standard [5]: e.g., "The choice of the elements of the physical system to be modeled is dependent on the definition of the goal and scope of the study."

\section{Conclusions and implications for future work}

The distinction between accounting LCAs and change-oriented LCAs is important, and it may be used as a guiding principle for methodological choices in a LCI. Recognizing the distinction is a first step not only towards recognizing that the choice of LCI methodology must depend on the goal and scope of the study, but also towards seeing how methodological choices are related to the goal definition.

In revised versions of LCA guidelines, especially the ISO standard, the distinction should be recognized, down to details such as recommendations on allocations procedures.

Further work is needed to describe in greater detail how use of marginal capacity should be modeled (what type of marginal) depending on which decision is being considered, and which ways to enlarge the system are most relevant to various goal and scope definitions. A framework is given in the LCANET report [4]; its applicability needs to be demonstrated in case studies.

The implications for impact assessment of this distinction (retrospective and prospective LCAs) need to be clarified. Given that relationships between doses and effects are seldom linear, the distinction probably is relevant for impact assessment, at least concerning the choice between average and marginal data.

\section{Acknowledgments}

This paper was first presented as a keynote lecture for the session on The Role of LCA in Decision Making at the SETAC-Europe annual 
meeting in Bordeaux, 14-18 April 1998. I am grateful to the Society of Environmental Toxicology and Chemistry (SETAC) for giving me that opportunity and thus prompting me to express, formulate and share my ideas on this subject.

\section{References}

[1] Baumann H. Decision Making and Life Cycle Assessment. Licentiate thesis. Göteborg: Chalmers University of Technology. Technical Environmental Planning Report 1995:4. (Also available as AFR Report 77. Stockholm: Swedish Waste Research Council.)

[2] International Standardization Organization. Environmental Management-Life Cycle Assessment-Principles and Framework. International standard ISO 14040, 1st ed. 199706-15. Geneva: ISO, 1997.

[3] Baumann H. Life Cycle Assessment and Decision Making: Theories and Practices. Ph.D. thesis. Göteborg, Sweden: Chalmers University of Technology, 1998. (Also available as AFR Report 183. Stockholm: Swedish Waste Research Council.)

[4] Frischknecht, R. Goal and scope definition and inventory analysis in LCANET, European network for strategic life cycle assessment research and development. In: Udo de Haes H, Wrisberg H, editors. LCA documents (Vol. 1). Bayreuth, Germany: Eco-Informa Press, 1997.

[5] International Standardization Organization. Environmental Management—Life Cycle Assessment-Goal and Scope Definition and Inventory Analysis. International standard ISO 14041, 1st ed. 1998-10-01. Geneva: ISO, 1998.

[6] Tillman A-M, Svingby H, Lundström H. Life cycle assessment of municipal waste water systems. Int J LCA 1998;3(3):145-57.

[7] Ekvall T, Tillman A-M. Open-loop recycling: criteria for allocation procedures. Int J LCA 1997;2(3):155-62.

[8] Huppes G. A general method for allocation in LCA. In: Huppes G, Schneider F, editors. Proceedings of the European Workshop on Allocation in LCA (Leiden, February 1994). Brussels: SETAC-Europe, 1994, 74-90.

[9] Clift R, Frischknecht R, Huppes G., et al. Towards a coherent approach to life cycle inventory analysis. Report from the SETAC Working Group on the Enhancement of Life Cycle Inventory Analysis. In preparation. Summary published in SETAC-Europe News 1999;10(3):14-20.

[10] Swedish Environmental Management Council (MSR). Requirements for certified environmental product declarations, general principles and procedures. AB Svenska Miljöstyrningsrådet 15 May 1998. MSR 1998:1. Available at: http://www.miljostyrning.se.

[11] Tillman A-M. LCA-baserade miljövarudeklarationer typ III. Utvärdering av manual: Rekommendationer till vidare utveckling (LCA-Based Environmental Product Declarations Type III. Evaluation of Manual: Recommendations for Further Development). CPM Report 1998:4. Göteborg, Sweden: Centre for Environmental Assessment of Product and Material Systems (CPM), Chalmers University of Technology.

[12] Society of Environmental Toxicology and Chemistry. Guidelines for Life-Cycle Assessment: A Code of Practice. Brussels: SETAC, 1993. 